\title{
A Case Study of Damage Energy Analysis and an Early Warning by Microseismic Monitoring for Large Area Roof Caving in Shallow Depth Seams
}

\author{
Like Wei, Qingxin Qi, Hongyan Li, Bin Zhang, Yongren Wang, and Linghai Kong \\ China Coal Research Institute, Mine Safety Technology Branch, No. 5 Qingniangou Road, Chaoyang District, Beijing 100013, China \\ Correspondence should be addressed to Like Wei; wlkyo@qq.com
}

Received 12 November 2014; Accepted 17 February 2015

Academic Editor: Shimin Liu

Copyright (C) 2015 Like Wei et al. This is an open access article distributed under the Creative Commons Attribution License, which permits unrestricted use, distribution, and reproduction in any medium, provided the original work is properly cited.

\begin{abstract}
Shallow depth coal seams are widely spread in Shendong mining area, which is located in the Northwestern region of China. When working face is advanced out of concentrated coal pillar in upper room and pillar goaf, strong strata behaviors often cause support crushing accidents, and potentially induce large area residual pillars instability and even wind blast disaster. In order to predict the precise time when the accident happens, guaranteeing life-safety of miner, microseismic monitoring system was for the first time applied in shallow coal seam. Based on damage mechanics correlation theory, the damage energy model is established to describe relationship between damage level and cumulative energy of microseismic events. According to microseismic monitoring data of two support crushing accidents, the damage energy model is verified and an effective early warning method of these accidents is proposed. The field application showed that the early warning method had avoided miners suffering from all support crushing accidents in Shigetai coal mine.
\end{abstract}

\section{Introduction}

The shallow depth coal seams which had been mined in the Shendong mining area have led to large area roof weighting frequently due to large thickness, high tensile strength, and small overlying load of the main roof. To prevent the large area roof weighting accidents, deep-hole presplit blasting technology for controlling roof caving is a suitable method and has been widely applied in some mines [1]. Furthermore, the mechanism and influence of these accidents have been exploited mainly by theoretical analysis, numerical simulation, and engineering verification [2-6], but prediction method of these accidents is barely analysed.

In geophysical techniques, seismic methods are widely applied to monitor and warn rock dynamic hazards in coal mines due to its abundant spectrum and broadband character, which can monitor the fracturing form of surrounding coal and rock, roof falls, and the high stress concentration distribution. During the past two decades, microseismic monitoring technique emerged from a pure research mean to a main stream industrial tool for daily safety monitoring at various fields of geotechnical engineering. In recent years, it has been widely applied in China. A microseismic monitoring system was for the first time installed for stability analysis of a high steep rock slope in China [7]. It has been proven to be very promising in instability prediction of rock slope subject to identification and delineation of potential slip surface and failure regions. Dou et al. [8] improve mining safety for water inrush in the goaf by more effective monitoring and proposed a monitoring method using partitioning and time sharing. According to a case study, the energy emission rate of microseismic events can be used to analyze the microseismic activity in time and the energy spatial density in space. Jiang et al. [9] investigate the progressive failure of geological structures (faults, karst collapse columns) and predicted water inrush with microseismic activities. Liu et al. [10] use an operation microseismic monitoring system of ESG to understand the relation between background stress field of three-dimensional numerical simulation with microseismicity and water inrush probability, combined with an engineering case of grout curtain community for Zhangmatun iron mine. Then, the accumulated three-dimensional 
geometry spaces of microrupture are delineated and the possible dangerous water inrush regions of grout curtain community are divided. Jiang et al. [11] analyzed and predicted that fracturing of high and thick strata of hard rocks causes strong dynamic response by theoretical calculation and microseismic monitoring based on high and thick strata of hard magmatic rock at working front 10416 in Yangliu coal mine. Lu and Dou [12] simulated and analyzed vertical stress concentration and gradient distribution rules by onsite monitoring of seismic, EME, and drilling bits volume for nearly a year in the whole mining process of 9202 working face in Sanhejian coal mine of Xuzhou coal mining group in China. Xia et al. [13] improved 5 risk forecasting indexes to predict coal mine rock burst with microseismic monitoring data. Zhu et al. [14] provided a new method for recognizing blasting vibration and rock fracture signals and use the calculated distribution feature of signals energy to recognize microseismic waveforms as feature index based on in situ microseismic data. Lu et al. [15] evaluated and monitor the danger and intensity of roof dynamic fracture by the evolution rules of frequency spectrum. With SOS MS monitoring system, the hard and weak roof fracture processes are measured in field. Yuan and Li [16] collected abundant microseismic signals by seismic monitoring system during the period of three pillar type rock bursts that occurred in number 11 mine of Pingmei group. The time sequence of microseismic signal in this period is obtained and the frequency spectrum and spatial distribution are analyzed by fast Fourier transformation (FFT) algorithm and fractal theory.

As an irreversible phenomenon, rock damage process was obtained by many experiments. Experimental study and theoretical research demonstrate that the damage evolution equation of rock based on analysis of energy dissipation can well characterize the damage evolution process of rock [17]. Wang et al. [18] proposed a rheological damage constitutive model for sandstone by using the damage theory and by introducing the concept of the whole process of damage into Burgers rheological model based on the Mazars damage evolution law. Zhang et al. [19] investigated the fatigue damage properties of intact sandstone samples subjected to axially cyclic loads with different frequencies at confining stress state and studied influence of frequency on dynamic mechanical features of sandstone by the MTS-815 rock and concrete test system. Acoustic emission tests under triaxial compression of limestone were carried out by MTS815 servocontrolled rock mechanical test system and AE21C acoustic emission monitor. Yang et al. [20] analyzed the characteristics of limestone damage evolution under triaxial compression through acoustic emission parameters.

Despite a great deal of work on application of microseismic monitoring system and analysis of rock damage process, there are a few reports about the relationship between rock damage process and the law of monitoring energy change by seismic monitoring system. In this paper, structure damage model will be established by damage mechanics theory based on the microseismic monitoring energy. Then, the damage characteristics of supporting-beam structure will provide a theoretical basis for an early warning method for large area roof caving in shallow depth seams.

\section{Accident Analysis}

Room and pillar mining was applied in Shendong mining area before large-scale exploitation, which controlled roof and surface subsidence by the remaining coal pillars to support mining. But the room and pillar mining is a low mining rate method, and it not only wastes a lot of resources but also forms a large area of room and pillar goaf and residual coal pillar. The residual coal pillar would form local stress concentration areas and increase difficulty of below contiguous seam mining.

With the increasing exploitation of strength, first primary mineable coal bed in Shendong mining area has been mined out mainly by room and pillar mining. Currently, longwall fully mechanized mining method is applied in second primary mineable coal bed. Due to close coal seam interval, strong strata behaviors would happen in mining face and even cause support crushing accident, such as accident in Shigetai coal mine of Wulan group [1-3], accident in Daliuta coal mine of Shenhua group $[4,5]$, and accident in Bulianta coal mine of Shenhua group [6].

There is large area of room and pillar goaf in 2-2 coal seam above 31201 working face in 3-1 coal seam in Shigetai coal mine of Shenhua group. According to geological conditions in Shigetai coal mine which is shown in Table 1, the depth of room and pillar goaf in 2-2 coal seam is about $81.3 \mathrm{~m}$. The distance between 2-2 coal seam and 3-1 coal seam is about $34.5 \sim 39 \mathrm{~m}$.

The depth of 31201 working face was about $120 \mathrm{~m}$ and the width of 31201 working face was about $300 \mathrm{~m}$. Threedimensional structure of 31201 working face is shown in Figure 1. In Figure 1, the direction of black arrow is the direction of face advance and blue zones include concentrated coal pillar and residual room pillars. Support which had $18000 \mathrm{KN}$ working resistance was applied in the face, but support crushing accident still happened in the midnight of December 16, 2013, when 31201 working face was mining $15.5 \mathrm{~m}$ out of concentrated coal pillar in upper room and pillar goaf. In the accident, 22\# 142\# support was crushed to death in less than 30 seconds and the descending amount of piston increased sharply to $1.3 \mathrm{~m} \sim 1.5 \mathrm{~m}$. Different field situations before and after accident are shown in Figure 2. The minimum oxygen concentration was $9 \%$ in return airflow corner and $14 \%$ in return airflow roadway. When the pressure was stable, the value of pressure gauge ranged from $45 \mathrm{MPa}$ to $80 \mathrm{MPa}(19300 \mathrm{KN} 34000 \mathrm{KN})$. Fortunately, the accident did not happen in working time, and no one was hurt in the accident.

According to the accident, support load was much higher than supporting ability, and the instantaneous value of pressure gauge in working face jumped to $800 \mathrm{bar}(34000 \mathrm{KN})$. Thus, there is no support which can resist the overwhelming pressure and the support crushing accident cannot be prevented only by support type choice. So, an early warning 
TABLE 1: Stratigraphic column of Shigetai mine.

\begin{tabular}{|c|c|c|c|c|}
\hline Stratigraphic order & Lithology & Average thickness/m & Depth/m & Lithological column \\
\hline 1 & Aeolian sand & 18.1 & 18.1 & \\
\hline 2 & Packsand & 15.9 & 34 & \\
\hline 3 & Siltstone & 16.2 & 50.2 & \\
\hline 4 & Packsand & 12.7 & 62.9 & \\
\hline 5 & $\begin{array}{l}\text { Medium granular } \\
\text { sandstone }\end{array}$ & 6.1 & 69 & \\
\hline 6 & Packsand & 8.2 & 77.2 & \\
\hline 7 & $2-2$ coal seam & 4.1 & 81.3 & \\
\hline 8 & Siltstone & 12 & 93.3 & \\
\hline 9 & $\begin{array}{l}\text { Medium granular } \\
\text { sandstone }\end{array}$ & 16 & 109.3 & \\
\hline 10 & Sandy mudstone & 8 & 117.3 & 3 \\
\hline 11 & 3-1 coal seam & 4 & 121.3 & \\
\hline 12 & Siltstone & 7.6 & 128.9 & \\
\hline
\end{tabular}

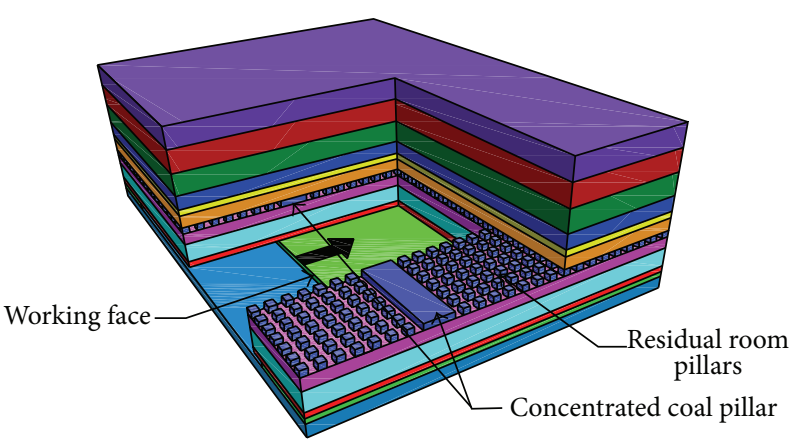

FIgURE 1: Three-dimensional structure of 31201 working face in Shigetai mine.

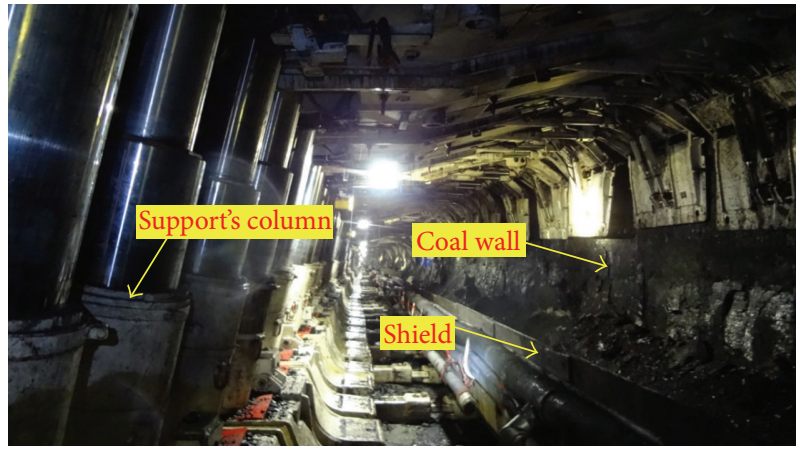

(a) Normal working face

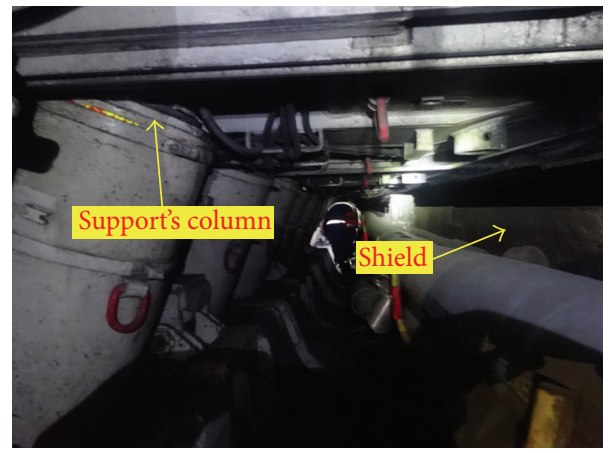

(b) Support crushing accident in working face

FIgURE 2: Comparison diagram in working face. 


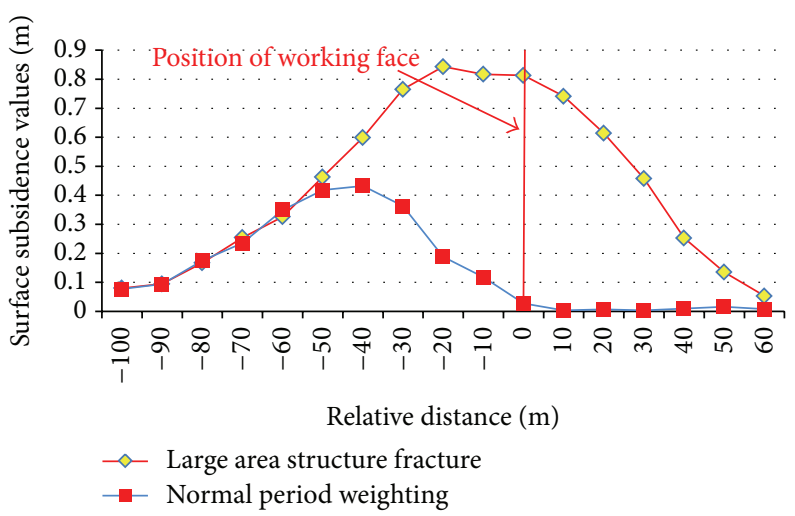

FIGURE 3: Surface subsidence values one day after two kinds of roof weighting.

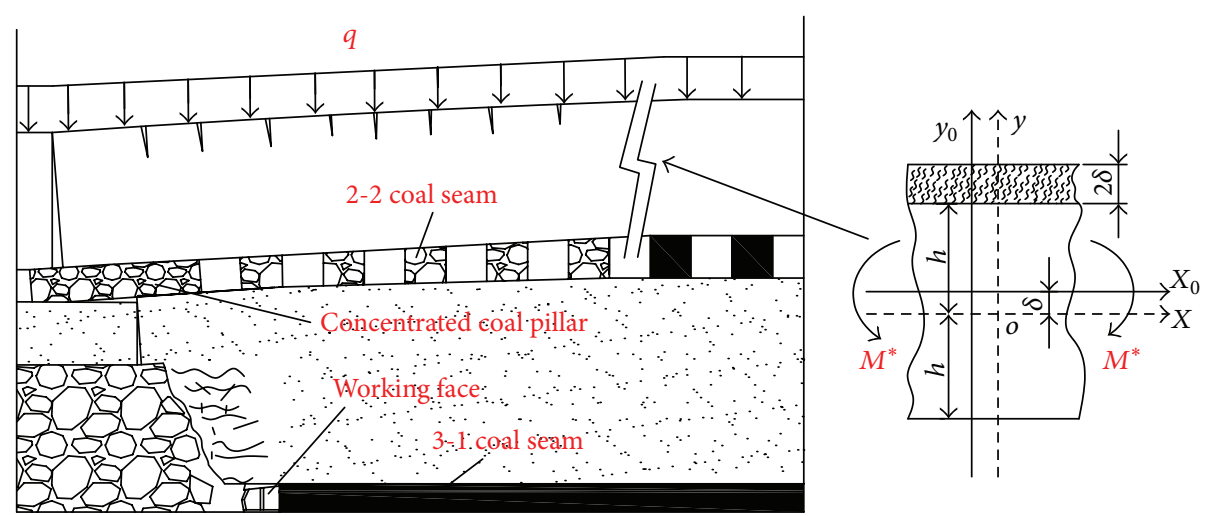

FIGURE 4: Supporting-beam structure damage model.

method will play an important role in guaranteeing life-safety of miners.

\section{Damage Energy Model}

3.1. Surface Subsidence Features. After roof weighting, surface subsidence values of this day can be obtained by the difference of measuring points altitude values in two neighboring days. For researching the difference between normal period weighting and large area roof weighting, the surface subsidence curve was used to measure roof sinking state in shallow depth seams. Along the middle line in the advancing direction above 31201 working face, measuring points in the surface subsidence curve were arrayed at intervals of $10 \mathrm{~m}$ from open-off cut to the stopping line. Figure 3 shows, respectively, curves of surface subsidence values one day after two kinds of roof weighting. It is obviously concluded from Figure 3 that when normal period weighting happens, only surface subsidence values of the measuring points behind the working face are obvious. But after large area structure fracture, obvious surface subsidence values will happen in measuring points in front of and behind the working face, and the values will be much bigger than the values caused by normal period weighting. Due to these phenomena, the difference of the two roof weighting is that large area roof weighting will cause 2-2 coal seam roof fracturing in front of working face position.

3.2. Supporting-Beam Structure Damage Model. The process of large area roof weighting can be abstracted to a model in the left diagram of Figure 4. The concentrated coal pillar starts to collapse after first roof weighting while mining out of concentrated coal pillar. Due to the high stress transfer process from concentrated coal pillar to residual room pillars, the maximum bending moment value of 2-2 coal seam roof will be gradually increased to its limit. And then, with 2-2 coal seam roof collapsing, large area of bending and sinking would happen in the roof of room and pillar goaf, causing large area of residual room pillars collapse. The weight of concentrated coal pillar and its upper strata would force on all supports in working face suddenly. Finally, the whole process would cause support crushing accident. Thus, the 2-2 coal seam roof plays a key role in support crushing accidents. In order to determine mechanism of these accidents, continuum damage mechanics model is established in maximum bending moment cross section of 2-2 coal seam roof, which is shown in the right diagram of Figure 4.

3.3. Damage Process Energy Analysis. Plenty of researches show that rock will inevitably release energy in the form of acoustic or seismic signals before its irreversible damage. 
Each seismic signal contains abundant information about the internal changes of rock mass. Seismic monitoring is a primary requirement for mining in rock burst coal mines. By analyzing the important parameters of seismic signals, such as seismic waves (P-wave and $\mathrm{S}$-wave) initial arrival time, moment, magnitude, and the epicenter coordinates, the reliable and important information for determining coal and rock fracturing energy and the corresponding dynamic disasters warning can be obtained [12].

In the process of roof fracturing, part of energy which is doing work by external force transfers to elastic energy of the structure and another part of it is dissipated by creating new cracks. Energy which can be monitored by microseismic monitoring system is exactly a part of the fracturing energy. So, total energy which can be monitored by microseismic monitoring system is defined by the following function:

$$
U=K(W-V) \text {, }
$$

where $W$ denotes the supporting-beam structure doing work by external force and $V$ is elastic energy which is transformed by part of $W . K$ is proportional coefficient of total energy which can be monitored by microseismic monitoring system to total fracturing energy in one roof weighting.

According to fracture mechanics theory [21], the energy release rate formula can be defined as

$$
G=\frac{d W}{d \widetilde{A}}-\frac{d V}{d \widetilde{A}}
$$

where $\widetilde{A}$ is the lost area.

Equation (3) can be easily derived from (2) and (1):

$$
\frac{d U}{d \widetilde{A}}=K G
$$

Damage variable of the supporting-beam structure is given by the relation

$$
D=\frac{A_{0}-A}{A_{0}},
$$

where $A_{0}$ denotes the initial area of the undamaged section in maximum bending moment cross section and $A$ can be interpreted as the actual area of the cross section. by

According to the beam geometry, the lost area $\widetilde{A}$ is related

$$
\widetilde{A}=A_{0}-A .
$$

Taking into account (5), by the derivation of (4), (6) can be obtained:

$$
\frac{d \widetilde{A}}{d D}=A_{0}
$$

Taking into account (3) and (6), energy data monitored by microseismic monitoring system per unit time is

$$
V_{U}=\frac{d U}{d t}=\frac{d U}{d \widetilde{A}} \frac{d \widetilde{A}}{d D} \frac{d D}{d t}=K G A_{0} \frac{d D}{d t} .
$$

In this paper, a formula of the damage evolution time of the supporting-beam structure with the exponential distribution is presented:

$$
D(t)= \begin{cases}0 & \left(t \leq t^{*}\right) \\ a e^{b\left(t-t^{*}\right)} & \left(t^{*} \leq t \leq t_{\max }\right),\end{cases}
$$

where both $a$ and $b$ are materials constants, which are related to stress state. $t^{*}$ is the moment when the stress at $y_{0}=h_{0}$ is maximal and $t_{\max }$ is the moment when $h$ is equal to zero.

Based on the cumulative energy data of microseismic events, (8) and (9) lead to the damage energy model

$$
\begin{aligned}
U(t) & =\int_{0}^{t} V_{U} d t=K G A_{0} D(t) \\
& = \begin{cases}0 & \left(t \leq t^{*}\right) \\
K A_{0} G a e^{b\left(t-t^{*}\right)} & \left(t^{*} \leq t \leq t_{\text {max }}\right) .\end{cases}
\end{aligned}
$$

Due to the fact that $D\left(t_{\max }\right)=1, U\left(t_{\max }\right)=K_{v} G A_{0}$. $U\left(t_{\max }\right)$ is the total cumulative energy which can be monitored by microseismic monitoring system in one roof weighting.

\section{Field Applications Analysis}

4.1. Microseismic Monitoring System. For monitoring seismic signal of supporting-beam structure while mining, a microseismic monitoring system, named KJ768, which is made by China coal research institution, was installed in 31201 working face. The KJ768 system has sophisticated hardware and powerful software features in data acquisition and data analysis. It is comprised of ground central station, GPS timer, exchanger, power, substation, and sensors. Series and parallel layout are shown in Figure 5.

Once the amount of sensors to be installed in 31201 working face is determined, it is necessary to conduct a reasonable arrangement of the sensors. Through theoretical analysis and field observation, the ultimate optimal arrangement and distribution of the twenty sensors are shown in Figure 6. Those twenty sensors are connected to three substations. With the advance of 31201 working face, the sensors will be moved forward one by one from one period to the next period and the width of every period is $210 \mathrm{~m}$. In Figure 6, four black sensors in ground surface are connected to one substation, five blue sensors in coal wall of air-return roadway and two red sensors in roof of air-return roadway are connected to one substation, and five blue sensors in coal wall of belt roadway and two red sensors in roof of auxiliary haulage roadway are connected to one substation.

The processing system in the central station digitizes the data with a sampling frequency of $60 \mathrm{kHz}$ and performs preliminary event detection when the recorded signals of three substations exceed a given threshold. Example waveforms of one artificial blasting test are shown in Figure 7, so constant P-wave and S-wave velocities are initially estimated from artificial blasting tests and used to calculate event locations. Then, the traces can be used to evaluate the energy size as well as the location of the event. 


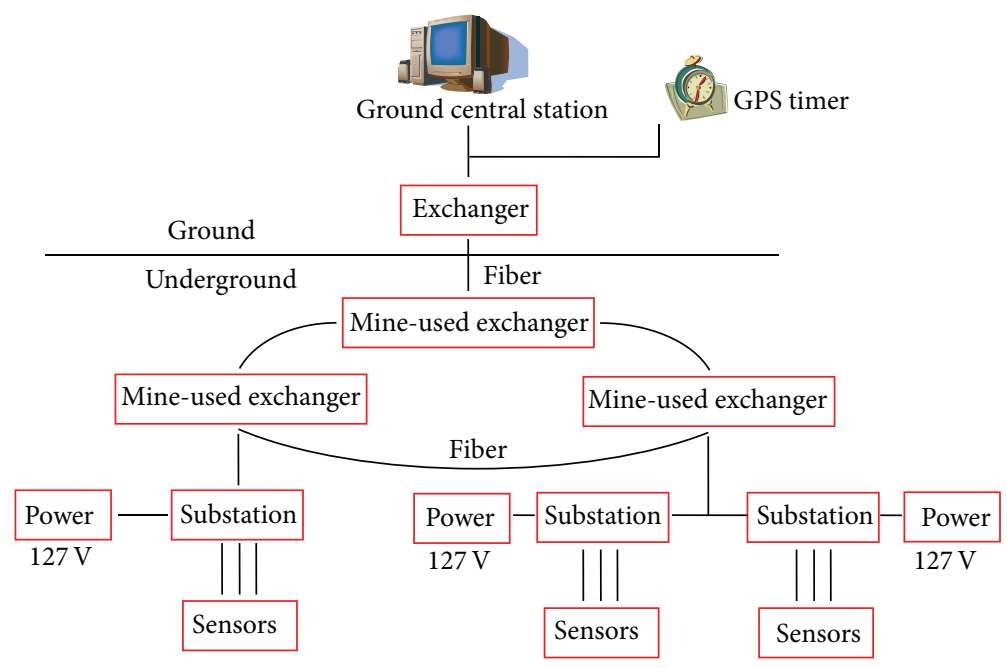

FIGURE 5: Example waveforms of a microseismic event recorded in artificial blasting test.

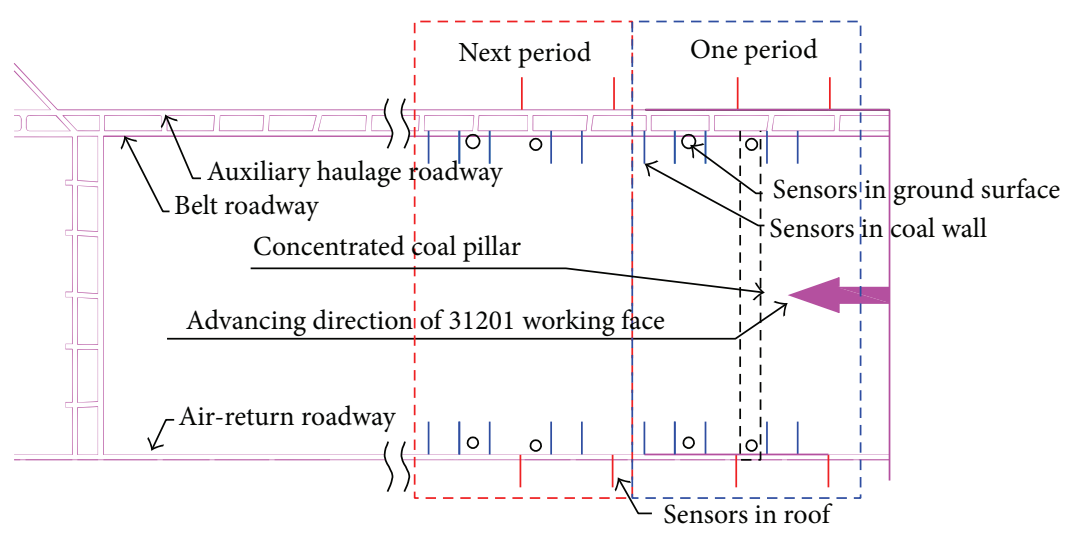

FIGURE 6: Sensors arrangement and distribution.

4.2. Damage Energy Application. The energy of microseismic events during the process of two supports crushing accidents that happened separately on the 20th of April and 22nd of April was monitored by KJ768. The relevant data of these processes are shown in Tables 2 and 3.

The curve of cumulative energy data of two large area roof weighting is described in Figure 8 by the data in Tables 2 and 3 . The result of curve fit analysis by damage energy model is shown in Table 4. Indexes of SSE, $R$-square, and RMSE indicate that fitting effects are very satisfactory. So, the damage energy model is suitable for describing variation law of cumulative energy which can be monitored by microseismic monitoring system in one roof weighting.

According to Figure 8, when the cumulative energy value of microseismic events was more than max cumulative energy value of microseismic events $U_{P \max }$ in normal roof weighting, the field monitoring process entered into warning region. Because time in damage energy model obeyed exponential distributions, when the cumulative energy value of microseismic events was more than $U_{P \max }$ and condition which was $U\left(t_{1}\right)>U\left(t_{2}\right)>U\left(\dot{t}_{\max }\right)$ satisfied $t_{1}>t_{2}$, a warning message was sent to inform miners escaping from the dangerous area in working face. After ending warning region, roof weighting appeared and caused supports crushing accident. Fortunately, thanks to the effective early warning method, life-safety of miners was guaranteed in these accidents. Thus, for life-safety of miners, warning time and escaping time must be sufficient in warning region.

4.3. Warning Area Analysis. For brittle material, damage evolution law equation can be assumed as follows:

$$
\dot{D}=C\left(\frac{\sigma}{1-D}\right)^{v}
$$

where $\sigma$ is the normal stress and both $c$ and $v$ are the materials constant.

According to supporting-beam structure damage model in Figure 4, at the stage of latent fracture, the normal stress in maximum bending moment cross section is given by

$$
\sigma=\frac{M^{*}}{I_{m 0}} y_{0}^{u}
$$


TABLE 2: Microseismic monitoring data on the 20th of April.

\begin{tabular}{lccccccc}
\hline Time & Energy/J & Time & Energy/J & Time & Energy/J & Time & Energy/J \\
\hline $8: 09: 04$ & $4.30 E+04$ & $15: 03: 49$ & $4.80 E+04$ & $16: 04: 04$ & $4.40 E+04$ & $17: 00: 44$ & $4.10 E+04$ \\
$8: 10: 19$ & $3.70 E+04$ & $15: 08: 29$ & $4.10 E+04$ & $16: 09: 29$ & $5.20 E+04$ & $17: 01: 04$ & $4.20 E+04$ \\
$8: 51: 19$ & $4.20 E+04$ & $15: 20: 29$ & $3.80 E+04$ & $16: 12: 14$ & $2.60 E+04$ & $17: 02: 04$ & $5.10 E+04$ \\
$9: 47: 54$ & $3.30 E+04$ & $15: 21: 04$ & $4.20 E+04$ & $16: 14: 44$ & $4.80 E+04$ & $17: 02: 14$ & $4.70 E+04$ \\
$9: 51: 14$ & $2.20 E+04$ & $15: 21: 44$ & $3.20 E+04$ & $16: 21: 54$ & $4.60 E+04$ & $17: 03: 09$ & $3.80 E+04$ \\
$11: 26: 14$ & $5.60 E+04$ & $15: 25: 04$ & $3.50 E+04$ & $16: 26: 34$ & $6.10 E+04$ & $17: 04: 54$ \\
$12: 20: 29$ & $5.00 E+04$ & $15: 25: 24$ & $4.30 E+04$ & $16: 32: 09$ & $4.60 E+04$ & $17: 05: 14$ \\
$12: 36: 54$ & $4.40 E+04$ & $15: 28: 19$ & $4.40 E+04$ & $16: 34: 14$ & $4.70 E+04$ & $17: 05: 19$ \\
$12: 38: 14$ & $5.10 E+04$ & $15: 31: 34$ & $3.00 E+04$ & $16: 38: 49$ & $5.10 E+04$ & $17: 06: 29$ & $3.50 E+04$ \\
$13: 08: 24$ & $2.10 E+04$ & $15: 36: 24$ & $4.20 E+04$ & $16: 41: 24$ & $4.10 E+04$ & $17: 06: 54$ & $3.70 E+04$ \\
$14: 16: 14$ & $4.20 E+04$ & $15: 38: 59$ & $5.20 E+04$ & $16: 41: 44$ & $6.40 E+04$ & $17: 06: 59$ & $5.10 E+04$ \\
$14: 20: 39$ & $4.30 E+04$ & $15: 40: 49$ & $4.80 E+04$ & $16: 43: 19$ & $3.50 E+04$ & $17: 07: 04$ \\
$14: 27: 44$ & $3.80 E+04$ & $15: 45: 04$ & $4.00 E+04$ & $16: 51: 44$ & $4.50 E+04$ & $17: 07: 39$ \\
$14: 35: 49$ & $3.90 E+04$ & $15: 45: 54$ & $4.70 E+04$ & $16: 52: 04$ & $4.40 E+04$ & $17: 07: 59$ & $3.30 E+04$ \\
$14: 39: 39$ & $2.80 E+04$ & $15: 54: 39$ & $3.50 E+04$ & $16: 54: 29$ & $5.90 E+04$ & $17: 08: 19$ \\
$14: 55: 24$ & $4.20 E+04$ & $15: 56: 09$ & $6.20 E+04$ & $16: 58: 39$ & $4.70 E+04$ & $17: 08: 29$ \\
$14: 55: 44$ & $4.60 E+04$ & $16: 02: 49$ & $5.00 E+04$ & $17: 00: 19$ & $3.80 E+04$ & $17: 09: 14$ & $5.20 E+04$ \\
\hline
\end{tabular}
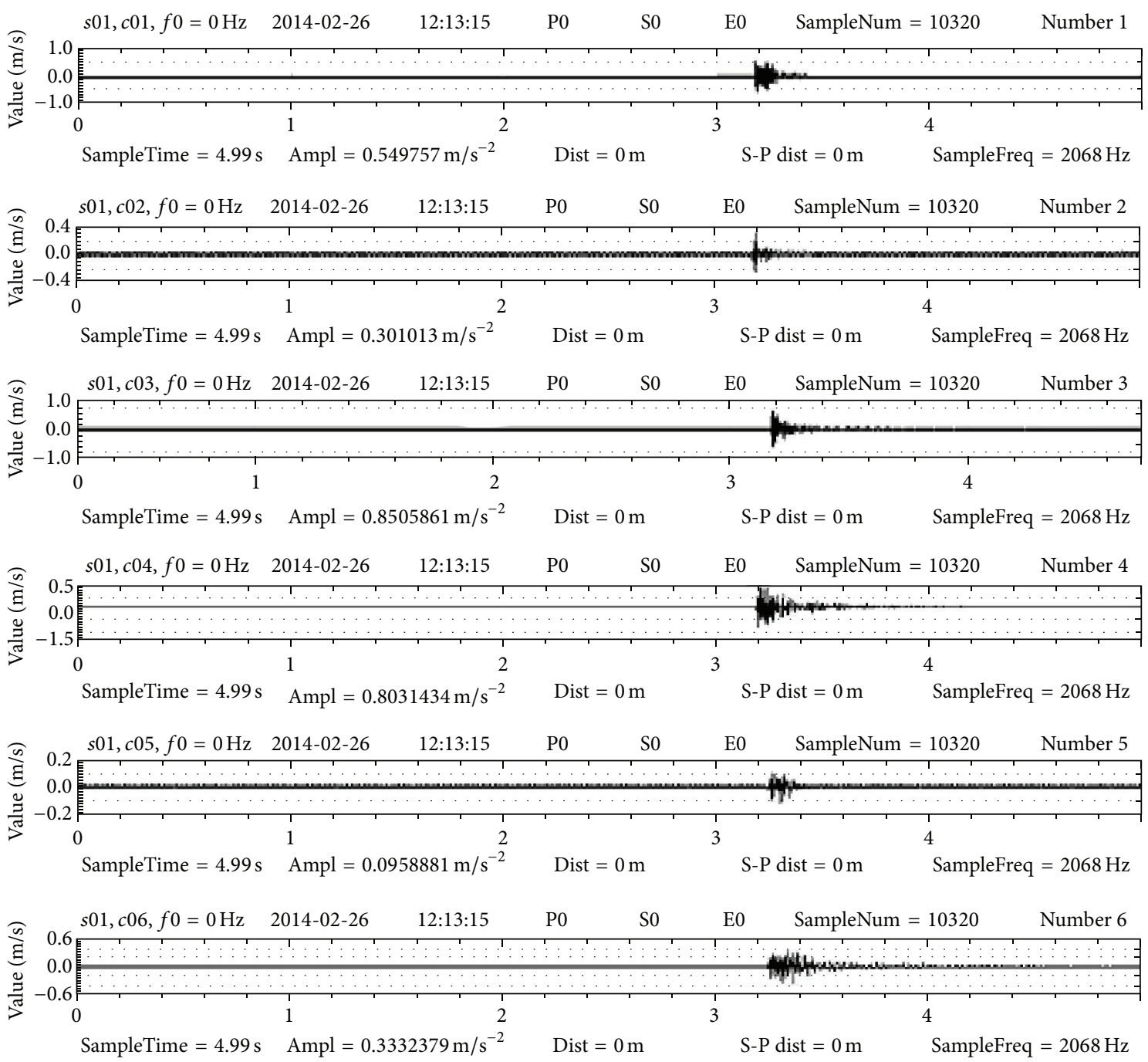

FIGURE 7: Example waveforms of a microseismic event recorded in artificial blasting test. 
TABle 3: Microseismic monitoring data on the 22nd of April.

\begin{tabular}{lccccccc}
\hline Time & Energy/J & Time & Energy/J & Time & Energy/J & Time & Energy/J \\
\hline $17: 38$ & $4.20 E+04$ & $21: 40$ & $5.00 E+04$ & $22: 25$ & $2.60 E+04$ & $22: 33$ & $4.20 E+04$ \\
$18: 23$ & $2.90 E+04$ & $21: 48$ & $5.70 E+04$ & $22: 27$ & $5.70 E+04$ & $22: 33$ & $3.50 E+04$ \\
$19: 20$ & $4.80 E+04$ & $21: 49$ & $5.00 E+04$ & $22: 28$ & $3.90 E+04$ & $22: 34$ & $3.00 E+04$ \\
$19: 23$ & $5.00 E+04$ & $22: 02$ & $6.90 E+04$ & $22: 28$ & $4.00 E+04$ & $22: 34$ & $4.30 E+04$ \\
$19: 27$ & $5.80 E+04$ & $22: 02$ & $5.10 E+04$ & $22: 29$ & $5.20 E+04$ & $22: 35$ & $3.30 E+04$ \\
$19: 30$ & $6.00 E+04$ & $22: 05$ & $3.20 E+04$ & $22: 29$ & $3.60 E+04$ & $22: 35$ & $5.00 E+04$ \\
$20: 17$ & $5.60 E+04$ & $22: 12$ & $6.10 E+04$ & $22: 29$ & $6.60 E+04$ & $22: 36$ & $6.90 E+04$ \\
$20: 17$ & $6.30 E+04$ & $22: 17$ & $4.50 E+04$ & $22: 30$ & $3.60 E+04$ & $22: 38$ & $4.40 E+04$ \\
$20: 49$ & $5.00 E+04$ & $22: 17$ & $5.80 E+04$ & $22: 31$ & $4.30 E+04$ & $22: 38$ & $5.30 E+04$ \\
$21: 08$ & $5.40 E+04$ & $22: 19$ & $4.50 E+04$ & $22: 31$ & $4.40 E+04$ & $22: 40$ & $6.40 E+04$ \\
$21: 15$ & $4.10 E+04$ & $22: 19$ & $6.40 E+04$ & $22: 31$ & $4.40 E+04$ & $22: 42$ & $3.80 E+04$ \\
$21: 39$ & $2.40 E+04$ & $22: 23$ & $3.90 E+04$ & $22: 32$ & $5.30 E+04$ & & \\
\hline
\end{tabular}

TABLE 4: Fitting parameters.

\begin{tabular}{|c|c|c|c|c|c|c|}
\hline \multirow{2}{*}{ Date } & \multirow{2}{*}{$U\left(t_{\max }\right) / J$} & \multirow{2}{*}{$a$} & \multirow{2}{*}{$b$} & \multicolumn{3}{|c|}{ Goodness of fit } \\
\hline & & & & SSE & $R$-square & RMSE \\
\hline 20th of April & $2.92 e+06$ & $4.35 e-03$ & 0.592 & $8.539 e+11$ & 0.983 & $1.137 e+05$ \\
\hline 22nd of April & $2.23 e+06$ & $7.78 e-04$ & 1.404 & $1.161 e+12$ & 0.9401 & $1.606 e+05$ \\
\hline
\end{tabular}

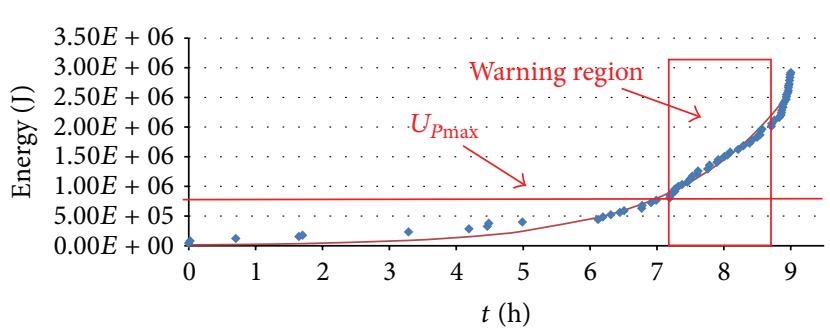

- Cumulative energy of microseismic events (J)

— Energy damage model

(a) Large area structural instability process during low-speed mining on the 20th of April

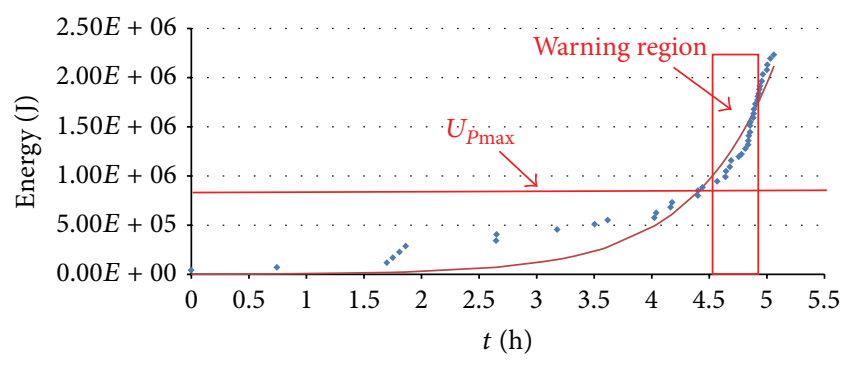

- Cumulative energy of microseismic events (J)

— Energy damage model

(b) Large area structural instability process during high-speed mining on the 22nd of April

FIGURE 8: Energy damage process comparisons between low-speed mining and high-speed mining.

where $M^{*}$ is the maximum bending moment in supportingbeam structure and $u$ is the materials constant. $I_{m 0}$ is the generalized moment of inertia.

According to the damage mechanics theory [22], latent fracture time when the stress reaches maximum is

$$
t^{*}=\left[(v+1) C\left(\frac{M^{*}}{I_{m 0}}\right)^{v} h_{0}^{u v}\right]^{-1},
$$

where $h_{0}$ is the initial height of the undamaged section in maximum bending moment cross section.

At $h=0$, the beam structure is completely fractured, and the corresponding time of fracture is

$$
t=\frac{2 n+1}{2 n-1} t^{*}=\frac{(2 n+1) I_{m 0}^{v}}{(2 n-1)(v+1) C h_{0}^{u v} M^{* v}} .
$$

According to formula (13), damage time which the beam structure needs to be completely fractured will be decreased in exponential level with the increase of the max bending moment $M^{*}$. It can be concluded from Figure 8 that, in the process of high-speed mining, observation time in warning area was only about half an hour, but observation time in warning area was increased rapidly to an hour and a half in the process of low-speed mining. Therefore, for increasing the finite observation time in warning area, the method of decreasing the max bending moment increasing speed by controlling mining speed was applied to obtain more time in warning area in the next similar situation.

\section{Conclusion}

Aiming at strong strata behaviors in shallow coal seam while mining out of the concentrated coal pillar in Shigetai coal mine of Shenhua group, microseismic monitoring system is 
for the first time applied in shallow coal seam. According to the features of ground surface subsidence, the supportingbeam structure damage model is established. Based on the damage mechanics correlation theory, formula of energy damage model is deduced to describe the change laws of cumulative energy of microseismic events. Using energy data of two support crushing accidents, parameters of the formula are obtained by fitting test and an effective early warning method of these accidents is determined by the laws of formula. By adopting the microseismic monitoring system and mining speed controlling method while mining out of the concentrated coal pillar, the early warning method has successfully avoided miner suffering from all support crushing accidents in Shigetai coal mine.

\section{Conflict of Interests}

The authors declare that there is no conflict of interests regarding the publication of this paper.

\section{Acknowledgments}

This work was financially supported by the National Science and Technology Major Program of China (2011ZX05040002), the International Science \& Technology Cooperation Program of China (2011DFA61790), and the National Natural Science Foundation of China (51174272).

\section{References}

[1] F. Wang, S. Tu, Y. Yuan, Y. Feng, F. Chen, and H. Tu, “Deep-hole pre-split blasting mechanism and its application for controlled roof caving in shallow depth seams," International Journal of Rock Mechanics and Mining Sciences, vol. 64, pp. 112-121, 2013.

[2] Q. Bai, S. Tu, F. Wang, and Y. Yuan, "Stress evolution and induced accidents mechanism in shallow coal seam in proximity underlying the room mining residual pillars," Chinese Journal of Rock Mechanics and Engineering, vol. 31, no. 2, pp. 3772-3778, 2012.

[3] S. H. Tu, F. J. Dou, Z. J. Wan, F. T. Wang, and Y. Yuan, "Strata control technology of the fully mechanized face in shallow coal seam close to the above room-and-pillar gob," Journal of the China Coal Society, vol. 36, no. 3, pp. 366-370, 2011.

[4] J.-F. Ju, J.-L. Xu, W.-B. Zhu, and X.-Z. Wang, "Mechanism of strong strata behaviors during the working face out of the upper dip coal pillar in contiguous seams," Journal of the China Coal Society, vol. 35, no. 1, pp. 15-20, 2010.

[5] J.-F. Ju and J.-L. Xu, "Influence of leading instability in the upper dip coal pillar boundary to the strong strata behaviors during the working face out of the pillar," Journal of the China Coal Society, vol. 37, no. 7, pp. 1080-1087, 2012.

[6] J.-F. Ju and J.-L. Xu, "Prevention measures for support crushing while mining out the upper coal pillar in close distance shallow seams," Journal of Mining and Safety Engineering, vol. 30, no. 3, pp. 323-330, 2013.

[7] N. W. Xu, C. A. Tang, L. C. Li et al., "Microseismic monitoring and stability analysis of the left bank slope in Jinping first stage hydropower station in southwestern China," International Journal of Rock Mechanics and Mining Sciences, vol. 48, no. 6, pp. 950-963, 2011.
[8] L.-M. Dou, J. He, S.-Y. Gong, Y.-F. Song, and H. Liu, "A case study of micro-seismic monitoring: goaf water-inrush dynamic hazards," Journal of China University of Mining \& Technology, vol. 41, no. 1, pp. 20-25, 2012.

[9] F. Jiang, G. Ye, C. Wang, D. Zhang, and Y. Guan, "Application of high-precision microseismic monitoring technique to water inrush monitoring in coal mine," Chinese Journal of Rock Mechanics and Engineering, vol. 27, no. 9, pp. 1932-1938, 2008.

[10] C. Liu, C. Tang, L. Li, Z. Liang, and S. Zhang, "Analysis of probability of water inrush from grout curtain based on background stress field and microseismicity," Chinese Journal of Rock Mechanics and Engineering, vol. 28, no. 2, pp. 366-372, 2009.

[11] J. Jiang, P. Zhang, L. Nie, H. Li, L. Xu, and W. Wang, "Fracturing and dynamic response of high and thick stratas of hard rocks," Chinese Journal of Rock Mechanics and Engineering, vol. 33, no. 7, pp. 1366-1374, 2014.

[12] C.-P. Lu and L.-M. Dou, "The relationship between vertical stress gradient, seismic, and electromagnetic emission signals at Sanhejian coal mine, China," International Journal of Rock Mechanics \& Mining Sciences, vol. 70, pp. 90-100, 2014.

[13] Y.-X. Xia, L.-J. Kang, Q.-X. Qi et al., "Five indexes of microseismic and their application in rock burst forecastion," Journal of the China Coal Society, vol. 35, no. 12, pp. 2011-2016, 2010.

[14] Q. Zhu, F. Jiang, Z. Yu, Y. Yin, and L. Lu, "Study on energy distribution characters about blasting vibration and rock fracture microseismic signal," Chinese Journal of Rock Mechanics and Engineering, vol. 31, no. 4, pp. 723-730, 2012.

[15] C. Lu, L. Dou, X. Guo, B. Liu, Z. Lu, and J. Fan, "Frequencyspectrum characters of microseismic signals induced by roof stratum fracture," Chinese Journal of Rock Mechanics and Engineering, vol. 29, no. 5, pp. 1017-1022, 2010.

[16] R. Yuan and H. Li, "Distribution of microseismic signal and discrimination of portentous information of pillar type rockburst," Chinese Journal of Rock Mechanics and Engineering, vol. 31, no. 1, pp. 80-85, 2012.

[17] R. Peng, H. Xie, and Y. Ju, "Analysis of energy dissipation and damage evolution of sandstone during tensile process," Chinese Journal of Rock Mechanics and Engineering, vol. 26, no. 12, pp. 2526-2531, 2007.

[18] W. Wang, J. Lu, H. Wang, and S. Sun, "A rheological damage model of sandstone and its application to engineering," Chinese Journal of Rock Mechanics and Engineering, vol. 31, no. 2, pp. 3650-3658, 2012.

[19] S. Zhang, E. Liu, and J. Zhang, "Experimental study of fatigue damage properties of sandstone samples under cyclic loading with low frequencies," Chinese Journal of Rock Mechanics and Engineering, vol. 33, no. 1, pp. 3212-3218, 2014.

[20] Y. Yang, D. Wang, M. Guo, and B. Li, "Study of rock damage characteristics based on acoustic emission tests under triaxial compression," Chinese Journal of Rock Mechanics and Engineering, vol. 33, no. 1, pp. 98-104, 2014.

[21] C. Shen, Fracture Mechanics, Tongji University Press, Shanghai, China, 1996.

[22] S. Yu and X. Feng, Damage Mechanics, Tsinghua University Press, Beijing, China, 1997. 

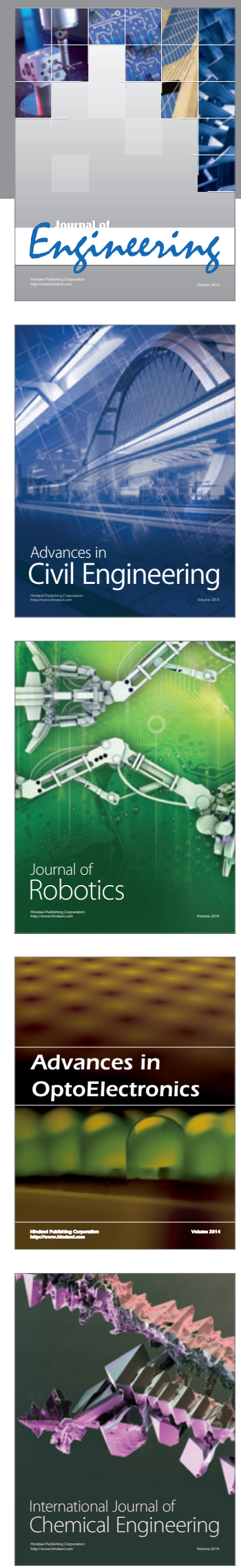

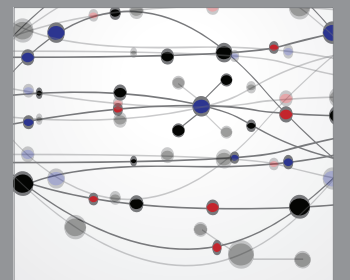

The Scientific World Journal
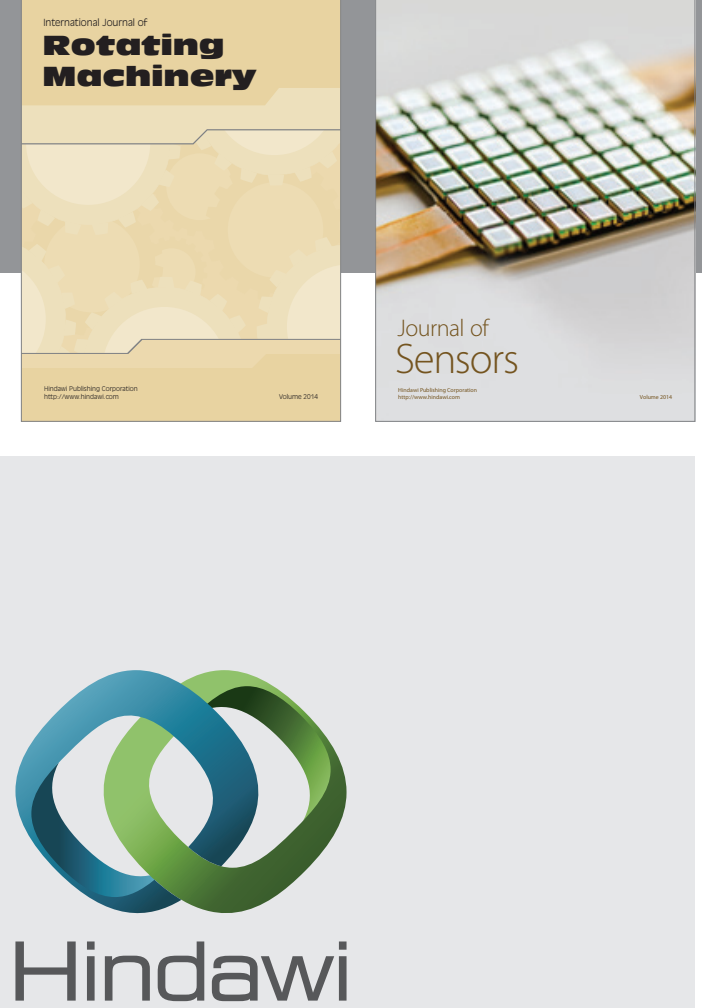

Submit your manuscripts at http://www.hindawi.com
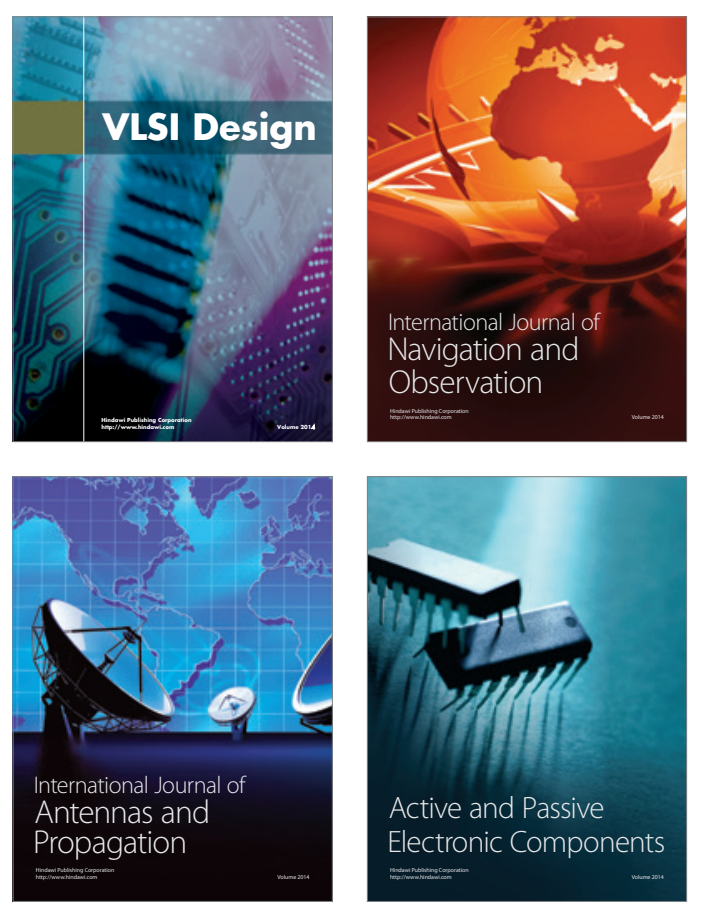
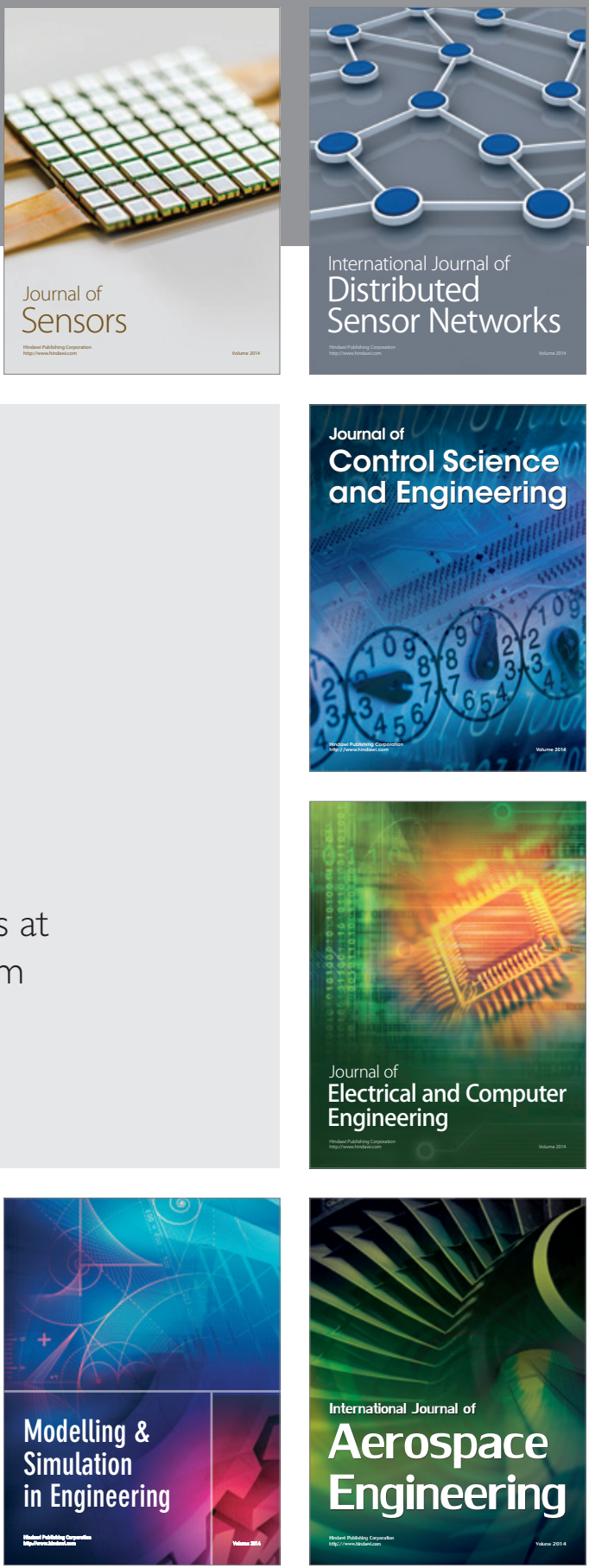

Journal of

Control Science

and Engineering
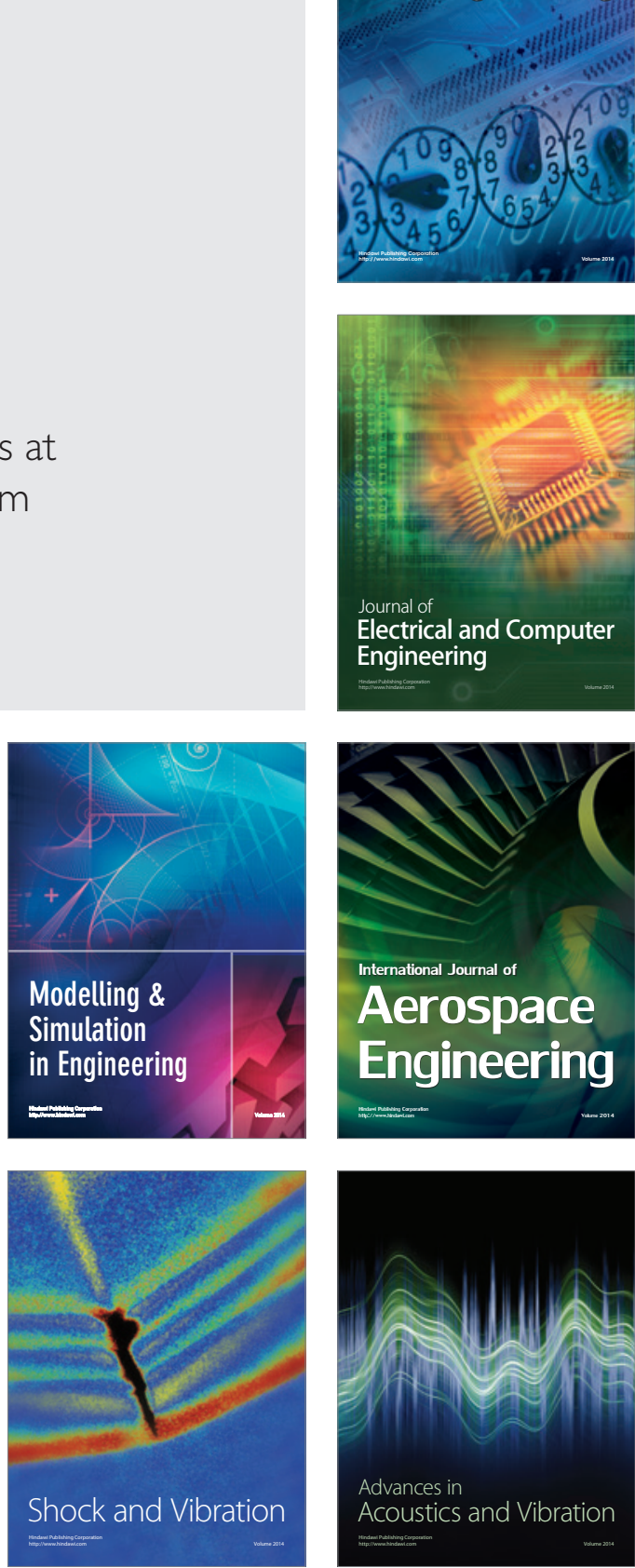